\title{
БЕЗОПАСНОСТЬ
}

\section{БЕЗОПАСНОСТЬ НА ТРАНСПОРТЕ в эпоху Интернета вещей}

DOI: $10.22184 / 2070-8963.2019 .81 .4 .36 .41$

XII Международная научно-практическая конференция "Системы безопасности на транспорте", организованная АО "Научно-исследовательский и проектно-конструкторский институт информатизации, автоматизации и связи на железнодорожном транспорте" (НИИАС) и Iskratel Group под эгидой Академии электротехнических наук РФ, состоялась в середине апреля в Словении в г. Блед. В ней приняли участие представители отраслевой науки, производственных компаний и организаций из России, Словакии, Словении, США, Чешской Республики. Особое внимание на конференции было уделено решениям для железных дорог и Интернету вещей.

\section{ПОчEMY ISKRATEL?}

Словенский инфотелекоммуникационный вендор Iskratel Croup (далее - Iskratel) уже третий год подряд выступил соорганизатором конференции "Системы безопасности на транспорте" (и, нельзя не отметить, он справился с этой задачей блестяще). Напомним, решения Iskratel в России уже 25 лет продвигает компания "ИскраУралТЕЛ", специалисты которой также активно участвуют в разработке этих решений.

Iskratel в лице "ИскраУралТЕЛ" давно и прочно завоевала место на телекоммуникационном рынке нашей страны как поставщик передовых и в то же время экономичных решений для операторов связи. Но при этом компания с головным офисом в городе Крань в течение многих лет разрабатывает специальные решения для отдельных отраслей.

И первым вертикальным рынком, где начало внедряться телекоммуникационное оборудование Iskratel, стал именно железнодорожный транспорт. Железнодорожные АТС для Югославских железных дорог марки ŽAT компания начала изготавливать в 1955 году. С тех пор специалистами Iskratel разработано большое количество специальных решений для железнодорожников. Например, для обеспечения технологической связи и безопасности на БайкалоАмурской магистрали поставлено несколько сот компактных программных коммутаторов SI3000 cCS.
Словенский вендор - одна из немногих компаний в мире, которая имеет опыт строительства сетей мобильной связи для железнодорожников стан дарта GSM-R. А в последние годы компания сделала и внедрила существенные наработки в области безопасности. Все перечисленное объясняет то, что Iskratel вполне логично была выбрана соорганизатором одной из ведущих научно-практических конференций транспортной отрасли.

\section{В ЦЕНТРЕ ВНИМАНИЯ - ЦИФРОВИЗАЦИЯ}

Открыл конференцию президент Академии электротехнических наук РФ член-корреспондент РАН Павел Анфимович Бутырин, отметивший большую актуальность включенных в программу тем. Практически все из них касались вопросов цифровизации транспорта с наибольшей долей железнодорожной тематики. В то же время конференция предоставила возможность обмена информацией о стратегии между различными видами транспорта, что позволит более оптимально расходовать средства на цифровизацию.

От имени словенского организатора участников приветствовал Матей Приятель, директор по развитию бизнеса "ИскраУралТЕЛ". Он поблагодарил учредителей конференции за то, что они уже в третий раз доверили Iskratel Group подключиться к ее проведению. 
С ключевым докладом о стратегии развития цифровой железной дороги с учетом вопросов обеспечения безопасности и кибербезопасности выступил один из основателей конференции - д.т.н. Ефим Наумович Розенберг, председатель Проблемного совета АЭН РФ, первый заместитель генерального директора АO "НИИАС". АО "НИИАС" определено головной организацией по внедрению систем управления и обеспечения безопасности движения поездов, а также технических средств железнодорожной автоматики.

Как рассказал докладчик, концепция "цифровой железной дороги" является основой развития современных железных дорог в России и в мире. Концепция представлена в "Дорожной карте цифровых железных дорог" МСЖД, а также сформулирована в рамках программы инновационного развития железнодорожного транспорта Европейского Союза Shift2Rail. Ключевым блоком Shift2Rail является программа IP2 "Инновационные системы управления и обеспечения безопасности движения поездов", охватывающая такие направления, как беспилотное управление, безопасная система позиционирования поезда с применением спутниковой навигации, виртуальная сцепка, кибербезопасность и др.

Е.Н.Розенберг подчеркнул, что российские железнодорожники из всех отраслей транспорта наиболее готовы к цифровизации благодаря сохранению централизованной структуры, отраслевых НИИ и вузов. В ОАО "РЖД" разработана и успешно реализуется Комплексная программа инновационного развития на период 2016-2020 годов. По словам докладчика, цифровизация железнодорожного транспорта требует наличия достоверной информации о состоянии подвижных объектов и инфраструктуры, а также предусматривает обязательное цифровое описание объектов в рамках единых координатных систем. На сети ОАО "РЖД" внедряется высокоточная координатная система (BKC) на основе ГЛОНАСС, обеспечивающая переход на использование инновационных координатных методов в задачах управления инфраструктурой, перевозочным процессом и обеспечения безопасности движения поездов. На основе высокоточных координатных моделей пути ведется совершенствование цифровых карт маршрутов, применяемых в составе оборудованных средствами ГНСС ГЛОНАCC/GPS бортовых комплексов управления и обеспечения безопасности движения поездов (КЛУБ-У, БЛОК).

Возможность периодического мониторинга с координатной привязкой данных о расстройствах пути и отклонениях от норм содержания в едином координатном пространстве ВКС позволяет получать и накапливать информацию об отказах по причине нарушения нормативов геометрии рельсовой колеи. Благодаря этому появляется возможность увязки данных различных измерений и их обработки с целью выявления критичных отклонений от нормативов и формирования предотказных состояний с использованием методологии УРРАН, а также внедрения аппаратно-программных средств Интернета вещей (IoT) и технологии Big Data. Kaк подчеркнул докладчик, пока всюду не будут установлены датчики IоT, говорить о цифровой железной дороге бессмысленно.

Большое внимание Е.Н.Розенберг уделил беспилотному движению. На сортировочной станции Лужская Октябрьской железной дороги успешно испытана технология роспуска вагонов с полностью автоматически управляемым горочным локомотивом. На полигоне тестируется технология телеуправления маневровым локомотивом с удаленного рабочего места оператора-машиниста. Ведется работа по адаптации данной технологии применительно к управлению движением пассажирских поездов на МЦК. Как подчеркнул докладчик, внедрение беспилотных технологий невозможно без

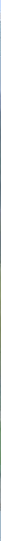

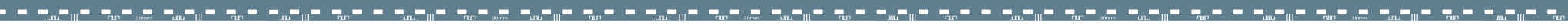


широкополосной беспроводной связи, такой как LTE, которая должна прийти на смену GSM-R.

Особое внимание российские железнодорожники уделяют вопросам кибербезопасности. Разработан пакет отраслевых документов, ведется планомер ная работа по проверке на киберзащищенность всех АСУ жТ, разрабатываются новые методологические подходы к обеспечению кибербезопасности систем управления ОАО "РЖД".

Темой доклада д.т.н. Леонида Аврамовича Баранова, заведующего кафедрой "Управление и защита информации" Российского университета транспорта (МИИТ), стала "Централизованная интеллектуальная система автоматического управ ления движением поездов на линиях городских железных дорог, как составляющая процесса циф ровизации". Как он отметил, существенной составляющей цифровизации в условиях метрополитенов и городских железных дорог (таких, как МЦК) является использование централизованной интеллектуальной системы автоматического управления движением поездов. Она состоит из подсистем: планирование перевозок; централизованного управления на линии; обеспечения безопасности движения; беспилотных поездных устройств управления; центра сбора данных; центра диспетчерского управления.

Подсистема планирования перевозок обеспечивает автоматическое построение планового графика движения, оборота состава, работы бригад обслуживания, передачу этой информации другим подсистемам и службам в виде, удобном для дальнейшего использования. Подсистема централизованного управления поездами на линии получает информацию о моментах прибытия и отправления всех составов по всем станциям и вырабатывает команды управления каждому поезду. Алгоритмы управления, используемые при компенсируемых возмущениях, называются графико-интервальными с первоочередным использованием ресурса стоянок.

Поезда с беспилотным управлением должны осуществлять регулирование времени хода с выбором энергооптимальных режимов управления, прицельного торможения (погрешность до 30 см) с замедлением. Бортовые системы обеспечивают безопасность движения, позиционирования поезда, измерение параметров движения, управление дверьми, функционирование радиоинформатора, реализуют обмен информации с центром управления. Дополнительно бортовые устройства реализуют торможение поезда по команде диспетчера, осуществляют диагностику подвижного состава и систем управления, фиксируют эксплуатационные показатели (пробег, осмотры и т.д.), передают информацию в центр сбора данных, что является необходимым для функционирования цифрового транспорта.

Наиболее важными функциями центра сбора данных являются: построение и хранение исполненных графиков движения при компенсируемых возмущениях, при больших сбоях, при восстановлении графика движения; сбор данных по результатам диагностики, по пробегам, осмотрам, ремонтам; создание "электронных двойников" подвижного состава; хранение информации о параметрах перегонов; настройки для каждого перегона регуляторов времени хода и прицельного торможения и др. Значительную роль при цифровизации играет банк имитационных моделей, позволяющий сравнивать эффективность решений по развитию технических средств, алгоритмов управления и структуры транспортного комплекса.

Тема цифровизации управления перевозками была продолжена в докладе заместителя генерального директора АО "НИИАС" д.т.н. Владимира Ильича Уманского "Цифровая трансформация управления перевозочным процессом на основе платформы Интеллектуальной системы управления железнодорожным транспортом (ИСУЖТ) и беспилотного вождения".

Как он подчеркнул, цель цифровой трансформации управления перевозочным процессом состоит не в попытке прямой автоматизации существующей технологии, а в качественном изменении парадигмы управления: превращении его в непрерывный адаптивный процесс планирования работы полигона и автоматического исполнения планов. Необходимо перейти от существующей системы децентрализованного планирования и индивидуального управления, для поддержки которой существует значительная совокупность слабосвязанных между собой информационно-аналитических систем, в лучшем случае ассистирующих различным диспетчерам, к централизованному планированию работы полигона и автоматическому исполнению принятых планов. Выполнить это возможно на основе цифрового двойника реального перевозочного процесса при реализации двухуровневой схемы управления: верхний уровень - полигоны, нижний - автоматическое управление маршрутами и движением локомотивов и станциями. На верхнем уровне в диспетчерском центре выполняется комплексное планирование работы полигона с балансировкой интересов погрузки, движения, содержания инфраструктуры, на уровне автоматического исполнения - управление пропуском 
поездов по участкам с координацией движения локомотивов, "подвязкой" бригад и подчинением работы станций общим интересам полигона.

Александр Александрович Романов, директор проектов цифровой экономики компании "ИскраУралТЕЛ", остановился на роли промышленного Интернета вещей (IIT) в задачах диагностики и мониторинга. Он отметил, что IIоT - это технологическая основа для перехода к новой экономической парадигме. Многие промышленные компании рассматривают его не только как способ снижения затрат с одновременным повышением производительности, но и как платформу для дальнейшего роста и эффективной конкуренции на рынке.

Внедрение технологий Интернета вещей предполагает использование большого количества датчиков, сенсоров, контроллеров, измерительных систем, которые собирают огромное количество различных данных (Big Data). Полученная информация может быть использована для предотвращения внеплановых простоев, поломок оборудования, сокращения внепланового техобслуживания и сбоев в управлении цепочками поставок. На сегодня лидером по внедрению IIоТ является транспортная отрасль. На нее приходится $16 \%$ от общего числа внедрений этой технологии. (Для сравнения: соответствующая доля индустрии умных зданий $-14 \%$, промышленности - 2,5\%, сельского хозяйства - 2\%, ритейла - 1,6\%). Применение технологий IIoT на транспорте позволяет осуществлять удаленный мониторинг технического состояния, обеспечивать безопасность и охрану, оптимизировать расписание и искать альтернативные маршруты. Так, одна из сфер, которыми занимаются специалисты "ИскраУралТЕЛ" - это предиктивный контроль оборудования перевода стрелок и подвесной контактной сети.

А.А.Романов подчеркнул, что для обработки и интерпретации большого массива неструктурированных данных требуется новый уровень аналитики. Для этого используются аналитические платформы, предназначенные для сбора, хранения и анализа данных о технологических процессах и событиях в реальном времени. В экосистеме IIоТ "ИскраУралТЕЛ" выбрала для себя роль разработчика платформы для управления, контроля и анализа данных и создания на их основе предсказательных моделей. Компания разрабатывает пользовательские приложения на основе своей платформы, а также занимается обработкой Big Data.

Одной из задач транспортной отрасли является формирование многофункциональных интермодальных хабов и транспортно-пересадочных узлов,

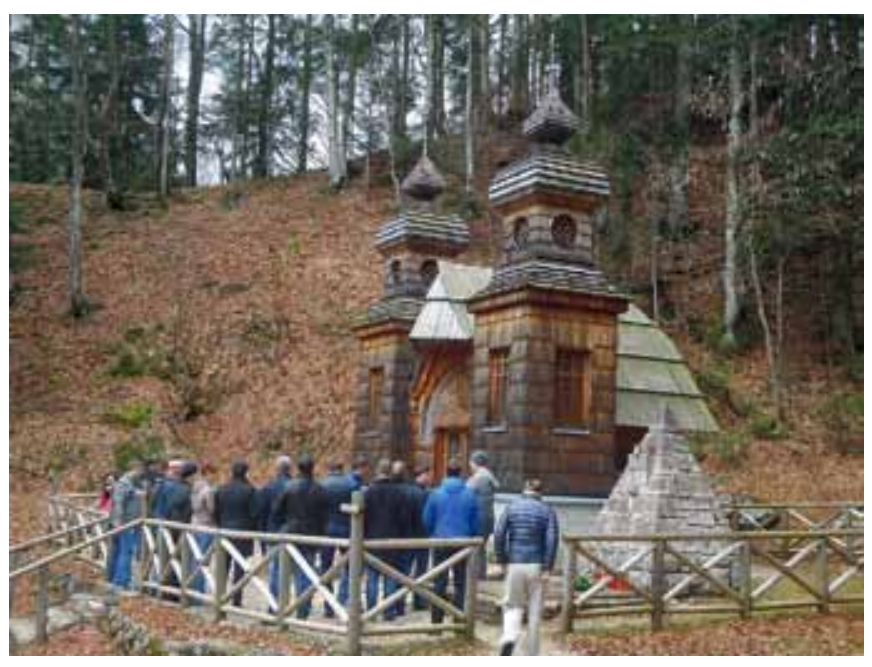

Участники конференции почтили у Русской часовни память соотечественников - солдат Первой мировой войны, погибших на перевале Вршич

интегрированных с современной городской средой и инфраструктурным окружением. Умная станция (вокзал) - это неотъемлемый и важный элемент умного города.

В области внедрения IIоT в железнодорожной отрасли "ИскраУралТЕЛ" сотрудничает в первую очередь с НИИАС и компанией "ЛокоТех-Сигнал". А.А.Романов подробно остановился на проекте по мониторингу и управлению территорией вокзалов, который реализуется специалистами "ИскраУралТЕЛ" совместно с Ростовским филиалом НИИАС. Пилотной площадкой стал вокзал Ростов Главный Северо-Кавказской железной дороги. Техническое решение указанного проекта предусматривает полевой уровень датчиков, платформу и портал, на котором в режиме реального времени отображается ситуация на вокзале, предоставляется статистика и аналитика о происходящих процессах. Платформа разработки "ИскраУралТЕЛ" обеспечивает сбор и обработку данных. В случае превышения пороговых значений на объектах информация в режиме реального времени доставляется в ситуационный центр для организации немедленного реагирования.

При планировании проекта ростовского вокзала функциональным заказчиком - АО "НИИАС" - поставлено несколько задач: повышение эффективности и безопасности вокзала, более точный учет расходов энергоресурсов, улучшение уровня наблюдаемости инженерных систем вокзала, повышение оперативности принятия решений дежурными службами на основании данных мониторинга, получение 


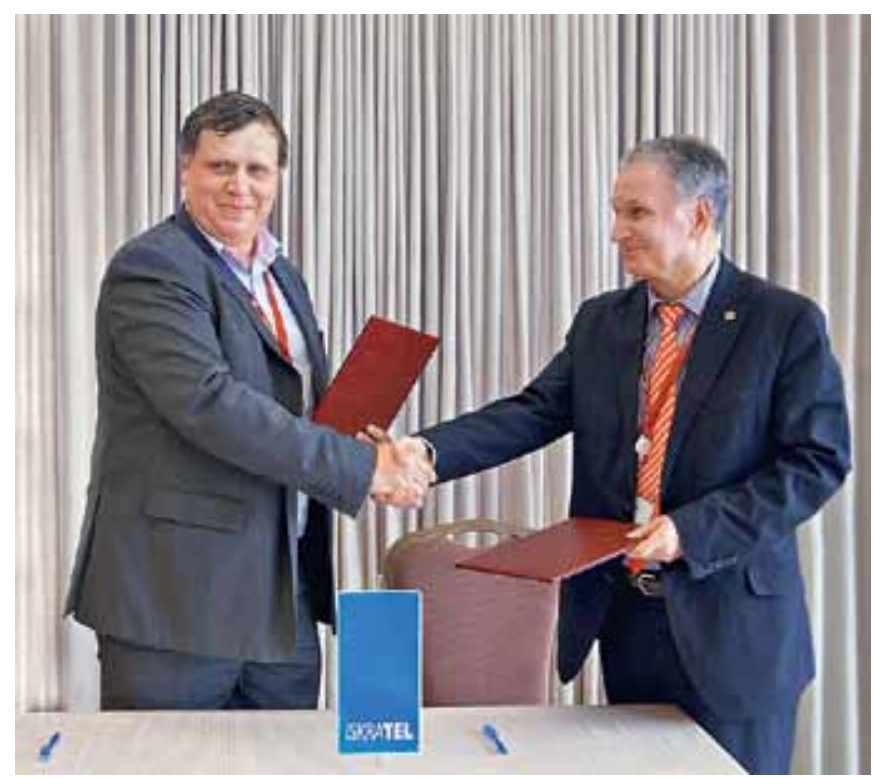

Подписание соглашения о сотрудничестве между АО "НИИАС" и Iskratel o.o.o.

опыта применения технологий IIоТ для автоматизации производственных процессов вокзалов.

Первый этап пилотного проекта успешно завершен. Сегодня в платформу IІоТ по беспроводной сети LoRaWAN поступает, хранится и обрабатывается информация примерно от 250 датчиков (от кон троля протечек воды и до занятия парковочного пространства на привокзальной площади) разных изготовителей, использующих различные протоколы, На очереди - интеграция умного вокзала со службами МЧС - Системой-112 и "Безопасным городом". Завершая свое выступление, А.А.Романов выразил уверенность, что развернутое в Ростове-на-Дону решение может быть тиражировано на другие вокзалы ОАО "РЖД".

Еще один доклад от Iskratel Group сделал Милан Миодрагович, главный инженер проектов. Он представил видение компанией концепции внедрения Интернета вещей на транспорте.

По словам докладчика, ожидается, что будущее транспортной отрасли во многом будет зависеть от интеллектуальных систем управления, использующих цифровые технологии, применение которых позволяет уменьшить стоимость жизненного цикла инфраструктуры. Новые услуги, такие как встроенная система безопасности, управление активами и система предиктивного технического обслуживания, позволяют усовершенствовать процесс принятия решений. Умный транспорт представляет собой сочетание взаимосвязанных технологических решений и компонентов, а также таких составных элементов современной транспортной инфраструктуры, какавтоматическая система продажи билетов, цифровые датчики и интеллектуальные счетчики.

Данные системы требуют беспроводного подключения для обеспечения высокоскоростной передачи данных и комплексных программных решений для оптимизации использования активов, удовлетворения требований обеспечения энергоэффективности и безопасности. Вместе с тем, поскольку такие системы все в большей степени используют беспроводную связь, они становятся более уязвимыми к внешнему воздействию, вмешательству и кибератакам. В связи с этим необходимо разрабатывать эффективные меры обеспечения безопасности и кибербезопасности.

М.Миодрагович рассказал о нескольких примеpax использования IIoT на транспорте, осуществленных как Iskratel, так и другими компаниями. В частности, по заказу железных дорог Республики Сербской (в составе Боснии и Герцеговины) специалисты Iskratel установили на локомотивах шлюзы IоT. Информация о местоположении поездов на основе GPS/GIS, направлении движения, средней скорости отображается на электронной карте железных дорог. Аналогичная информация появляется на дисплее машиниста. Внедренная система также осущест вляет в реальном времени централизованное автоматическое информирование и оповещение пас сажиров с учетом изменений. Проект будет развиваться - на втором этапе планируется внедрить учет пробега вагонов, которые уходят за границу страны. Затем будет обеспечен контроль за расходом тепловозами топлива.

На стадии подготовки к внедрению находится проект видеоаналитики для автомобильных дорог Хорватии. Благодаря использованию платформы IIоT оператор на своем рабочем месте может по любому перекрестку получить статистику, например, о числе автомобилей, проехавших на красный свет или превысивших допустимую скорость.

Хорошим примером внедрения технологий Интернета вещей является немецкий железнодорожный перевозчик DB Cargo. Эта компания для управления и контроля за движением поездов запланировала оборудование всех трех тысяч своих локомотивов шлюзами IIоT, причем эти шлюзы принимают на себя первичную обработку собираемой на локомотиве телеметрии. Далее информация через сеть GSM-R передается в центральное облако.

В заключение докладчик подытожил плюсы вне дрения технологий Интернета вещей:

- анализ огромного количества данных; 
- двухсторонний обмен данными между системами;

- защита информации на каждом уровне ее обработки;

- единое представление данных в графическом интерфейсе;

- единая платформа для удобных доставки новых приложений и подключения новых источников информации.

Тематика выступлений не ограничилась вопросами только железнодорожного транспорта. Так, американский консультант Дженнифер Трелевич (компания TGPO Consult) рассказала о подходах к построению системы предиктивного технического обслуживания в гражданской авиации с использованием алгоритмов обработки больших массивов данных Big Data.

В течение двух дней работы был рассмотрен и обсужден еще целый ряд тем - от организации систем управления на транспорте за рубежом и до проблем применения полупроводниковых преобразователей электроэнергии подвижного состава и аккумуляторных батарей. Доклады были представлены учеными Национального исследовательского университета "МЭИ", Российского университета транспорта, а также специалистами компаний-проектантов, разработчиков и производителей ("ЛокоТех-Сигнал", "МикроМакс Системс", "Гипро транссигналсвязь", "Экспериментальная мастерская НаукаСофт", "Позитив Текнолоджиз"). Наибольшее количество докладов традиционно было сделано ведущими специалистами АО "НИИАС".

\section{СОТРУДНИЧЕСТВО БУДЕТ КРЕПНУТЬ}

Конференцию на берегу живописного озера Блед (Блейского, как его называют сами словенцы), одной из визитных карточек страны, завершило торжественное событие: было подписано соглашение о сотрудничестве между АО "НИИАС" и компанией Iskratel o.o.o. Свои подписи поставили: от имени российского института - Е.Н.Розенберг, словенской компании - М.Приятель.

В рамках соглашения стороны намерены активизировать двустороннее взаимодействие в области развития современных систем мониторинга и диагностики, а также внедрения комплексных решений автоматизации объектов транспорта с применением цифровых платформ.

\section{Частоты для российских тестов $5 G$}

На заседании Государственной комиссии по радиочастотам (ГКРЧ) принято решение о расширении полосы частот, ранее выделенной под тестирование технологий связи пятого поколения (5С).

Учитывая распространенные характеристики оборудования для 5С, ГКРЧ увеличила разрешен- ный для тестирования 5С верхний диапазон с 25,2527,5 ГГц до 25,25-29,5 ГГц. Нижний диапазон 4,84,99 Ггц для тех же целей остался без изменений.

Кроме того, комиссия определила две дополнительные пилотные зоны для тестирования $5 \mathrm{C}$ в Москве - спорткомплекс "Лужники" и деловой центр "Москва-Сити". Ранее в качестве таких зон были определены инновационный центр "Сколково", ВДНХ, улица Тверская, Воробьевы горы, парки им. Горького и "Зарядье".

По информации Минкомсвязи РФ

\section{Константин Носков призвал изготавливать китайское оборудование 5 В в РФ}

Министр цифрового развития, связи и массовых коммуникаций РФ Константин Носков предложил локализовать в России производство китайского телекоммуникационного оборудования, в том числе под сети $5 \mathrm{C}$ и Интернет вещей. Об этом он заявил во время переговоров с министром промышленности и информатизации КНР Мяо Вэйем, которые прошли на полях третьей встречи министров по цифровым технологиям С20 в японской Цукубе.

"Рынок России в части спроса на телекомоборудование под строительство сетей $5 \mathrm{C}$ и Интернета вещей является достаточно большим, и партнерство стран в этом сегменте представляется перспективным. Однако основной спрос будет сформирован внутренним рынком России, где нормативно будут закреплены преференции локальным производителям, продуктам и решениям. Совместный российско-китайский проект по локализации производства на территории России позволит гарантировать спрос на оборудование для сетей связи 5С и устройств Интернета вещей", - сказал К.Носков.

Локализация решений Китая на территории России снизит риски зависимости от других зарубежных поставщиков, создаст спрос на оборудование и материалы китайского происхождения и общую научно-техническую базу для разработки новых технологий и продуктов, уверен министр. Он предложил китайскому коллеге проанализировать возможность переноса производства оборудования на территорию РФ и в сентябре более детально обсудить этот вопрос на заседании Российско-китайской подкомиссии по связи и информационным технологиям.

Кроме того, глава Минкомсвязи сообщил, что в России разработана программа по созданию более 200 дизайн-центров в области микроэлектроники. Ресурс этих центров может быть использован для проектирования изделий под рынки как России и КНР, так и третьих стран.

По информации Минкомсвязи РФ 